\title{
Let Me Tell You 'Bout the Birds and the Bee-Mimicking Flies and Bambiraptor ${ }^{1}$
}

\begin{abstract}
Scientists have been arguing for more than twenty-five years about whether it is a good idea to collect voucher specimens from particularly vulnerable biological populations. Some think that, obviously, scientists should not be harvesting (read: killing) organisms from, for instance, critically endangered species. Others think that, obviously, it is the special job of scientists to collect precisely such information before any chance of retrieving it is forever lost. The character, extent, longevity, and span of the ongoing disagreement indicates that this is likely to be a hard problem to solve. Nonetheless, the aim of this paper is to help field biologists figure out what do to when collecting a voucher specimen risks extinction. Here I present and assess varying practices of specimen collection for both extant (i.e., neontological) and extinct (i.e., paleontological) species in order to compare and contrast cases where extinction risk both is and is not a problem. When it comes to taking vouchers from extant species at some risk of extinction, I determine that those advocating for conservative approaches to collection as well as those advocating for liberal information-gathering practices have good reasons to assess things in the way they each do. This means that there is unlikely to be a decisive, one-size-fits-all response to this problem. Still, progress can be made. We can acknowledge the risks of proceeding in either manner, as well as the uncertainty about how best to proceed (which will be deep in some cases). We can proceed as thoughtfully as possible, and be ready to articulate a rationale for whichever procedure is used in any particular case.
\end{abstract}

Keywords: collection, conservation, extinction, species, taxonomy, vouchers

\section{Introduction}

What would you do if you happened upon an American ivory-billed woodpecker, and had the opportunity to collect it — a chance to document a species that has not been collected since 1925? A scientist once said to me, and not in private, "I would kill it. It's not even an ethical issue." But this person worked in collections, curation, and research—on one side of a particularly sharp divide within museum scientists.

On the other side of this particular division are the conservation biologists- some but not all of whom also work in museums. Recently, a handful of such scientists wrote a letter to Science, urging field biologists everywhere to change their collecting practices. The opening paragraph of that letter states:

Field biologists have traditionally collected voucher specimens to confirm a species' existence. This practice continues to this day but can magnify the extinction risk for small and often isolated populations. The availability of adequate alternative methods of documentation, including high-resolution photography, audio recording, and nonlethal sampling, provide an opportunity to revisit and reconsider field collection practices and policies. (Minteer, Collins, Love, \& Puschendorf 2014, 260)

As is often the case with scientific missives, there is quite a lot packed into that one small paragraph. The first sentence establishes the overall subject of the letter: the traditional collecting practices of field biologists. It also establishes some relevant terminology. Voucher specimens are a sort of specimen generally collected as part of an effort to demonstrate either that a new species has been discovered, or that a species once thought to be extinct has now been rediscovered. ${ }^{2}$ The second sentence articulates the authors' grounds for objecting, in certain circumstances, to the practice of collecting voucher specimens. These conservation biologists are

\footnotetext{
${ }^{1}$ By Joyce C. Havstad (jhavstad@gmail.com). Manuscript dated February 19, 2019. Forthcoming in a special issue on "Paleobiology and Philosophy" in Biology \& Philosophy.

${ }^{2}$ Type specimens are one kind of voucher.
} 
especially concerned with the threat of collection when the so-called voucher must be issued from a particularly vulnerable population. The third and final sentence declares that there are perfectly acceptable alternatives to the collection of vouchers - a process which, when dealing with extant animal populations, is called harvesting - and suggests that the field re-establish its routines. In essence, the letter is a call for reform issued by conservation biologists to field biologists at large: a plea to establish a new state of play, one that swaps the traditional practice of harvesting for photography and other substitutes, at least when interacting with especially fragile species.

It would be hard to overstate the vehemence of the many objections that were issued in response to this letter, and which generally came from the other half of this scientific dividefrom the collections, curation, and research side of things. The initial letter was published on April 18, 2014. On May 23, Science published a pair of replies (Rocha et al. 2014; Krell \& Wheeler 2014), as well as a response to these replies by three of the four authors of the original piece (Minteer, Collins, \& Puschendorf 2014). The replies alone took up more page space in the journal than the initial letter had; the first reply was signed by over a hundred scientists from museums and academies all over the world (Rocha et al. 2014). These replies each object, in their own ways, to both of the key claims articulated in the paragraph quoted above. The key claims from the initial letter are that the collection of voucher specimens constitutes an (unacceptable) magnification of the risk of extinction to vulnerable populations, and that there are perfectly acceptable, readily available alternatives (like photography) to specimen collection, even when trying to name new species. The replies to the initial letter dispute both of these points: they argue instead that voucher specimen collection poses no special risk to vulnerable populations, and that there are no genuine substitutes for harvesting. In one case, the respondents imply they wished field biologists would exert themselves to do more collecting than they currently do, declaring "We wish that B. A. Minteer et al.'s claim that field biologists routinely collect voucher specimens were true... Any museum curator will tell you that it is a constant struggle to convince them to do so... (Krell \& Wheeler 2014, 815).

This exchange in Science is not an isolated incident. Two years later-in the July 21, 2016 issue of Nature - a pithy editorial about "Virtual Taxonomy" was published. The editorial was written in the form of a guide to Pokémon Go players who might stumble upon not only imaginary organisms but also the occasional physical specimen representing a novel taxonomic discovery. The editorial asks you to imagine that you are just such a virtual explorer, armed only with a cell phone and its high-resolution camera: "So, say you do manage to snap a picture of something previously unknown to science - what then? Let Nature be your guide" (Unsigned 2016, 324). The "guide" then makes three claims about current taxonomic practice:

1. The Code of the International Commission on Zoological Nomenclature (ICZN) has recently been updated to recognize new species names published in online-only media.

2. Although there have been scientific attempts to name new species solely on the basis of photographs, you will probably have to collect an actual specimen in order for the discovery to be officially recognized.

3. If you do discover and thereby get to officially name a new species, you can likely name it after your mum, or even a politician, if you like.

Soon after the publication of this editorial, a short piece of correspondence from Thomas Pape of the Natural History Museum of Denmark was also published, in the September 15 issue of Nature. Pape's note was titled "Species can be named from photos" and it was in direct dispute with claim 2 above (Pape 2016). The author was supported by 34 signatories. In the November 10 issue of that same year, Nature published yet another follow-up note, one by Frank T. Krell of the Denver Museum of Nature \& Science, entitled "Preserve specimens for reproducibility," and joined by 5 
signatories. This note was in opposition to Pape's, as the title indicates (Krell 2016). Both Pape and Krell are current commissioners of the ICZN. ${ }^{3}$

Nature had, however, already refused (on October 18) to publish a different response to Pape's note, one submitted on September 25 (just 10 days after Pape's note was published) and titled "Photography-based taxonomy is inadequate, unnecessary, and potentially harmful for biological sciences." Despite Nature's refusal, the reply was published in Zootaxa on November 23 and, as the title indicates, it was deeply critical of Pape's note. The writers urged that the Code of the ICZN be rapidly reformed to clearly prohibit such purportedly detrimental taxonomic practice. This bit of correspondence originally intended for Nature was authored by Luis M. P. Ceríaco, Eliécer E. Gutiérrez, and Alain Dubois - three scientists with appointments at prestigious natural history museums in (respectively) Lisbon, Washington D.C., and Paris. But 493 other "collections-based researchers" (Ceríaco, Gutiérrez, \& Dubois 2016, 435) joined them in signing the letter; nearly 500 signatures were collected between September 20 and October 6 of 2016 .

This issue - of how to collect or not to collect voucher specimens, especially in adverse or otherwise fraught circumstances, and whether there are ever any truly acceptable alternatives to harvesting, like photography - is clearly one of significant note to museum scientists. It is an issue on which hundreds of researchers around the world are poised and ready, at a moment's notice, to add their names in support of the some of the most strongly-worded condemnations and invectives to be repeatedly issued in the current course of published scientific practice. Finally, the issue is one that has been simmering for quite some time. In 1991, the ornithological journal Ibis published report of a new species discovery and description - one based on type material that included DNA, both dried and fresh blood, moulted feathers, 50 color photographs, a video, and several audio tape recordings... but no traditional type specimen (Smith et al. 1991). The response was immediate and passionate: objections were issued in the Bulletin of the British Ornithological Club (LeCroy \& Vuilleumier 1992) and Trends in Ecology \& Evolution (Peterson $\&$ Lanyon 1992), among others. One objection printed in The Auk was authored by four ornithologists and signed by 98 others from 19 different countries (Banks et al. 1993). And the furor surrounding this particular episode has never really abated: the episode is mentioned in many if not most of the discussions of the ethics of collecting that have since occurred (e.g., Hustler 1996; Wakeham-Dawson, Morris, \& Tubbs 2002; Bates et al. 2004; Dalebout et al. 2004; Dubois \& Nemésio 2007; Donegan 2008, 2009; Nemésio 2009; Peterson 2014; Dubois 2017; Krell \& Marshall 2017). Newly controversial cases have since arisen (e.g., Jones et al. 2005; Thalmann \& Geissmann 2005; Mendes Pontes, Malta, \& Asfora 2006; Gentile \& Snell 2009; Marshall \& Evenhuis 2015), but the case of the provocatively-named Laniarius liberatus - the shrike that was set free-is the one that most prominently commences and persists throughout this modern period of discord surrounding biological specimen collecting practices. "They bungled it," said one ornithologist to me in 2015 , speaking of the purported discovery, approximately 25 years after the fact.

There are two questions we might ask about this ongoing dispute between the collections, curation, and research side of things and the conservation biology side. ${ }^{4}$ First: how might we best characterize the dispute between these two sides? Second, and perhaps more importantly: how might we best resolve the dispute? The aim of this paper is to answer both questions, working initially on characterization and then on resolution. The next section of the paper ("Free Bird") presents the details of the case upon which much of the dispute is founded. The section after that ("Characterizations") extrapolates from the founding case and other more recent ones, in order to

\footnotetext{
${ }^{3}$ At time of writing.

${ }^{4}$ Without necessarily endorsing this division, or presuming it to be constituted by anything more than whatever has produced or reflects the disagreement under discussion here.
} 
generate a comprehensive rather than selective account of the considerations in play. Selective accounts can lead to unproductive characterizations of the dispute, and several examples of this sort of unproductive characterization are identified in this section-both ones that disputants have employed, and ones that intervening philosophers might be tempted to employ. In the next section ("If We Hold On Together"), relevant paleontological collecting practices are compared to the neontological ones under dispute. ${ }^{5}$ This comparison - to related practices, but from a domain with fewer worries about collection contributing to extinction — suggests that procedure matters a great deal to all biological practitioners, whether neontological or paleontological. So, the penultimate section of the paper ("Resolutions") examines what the most authoritative source of current, zoological collection procedure says about collection, when collection risks extinction. This source (the ICZN) says that when collection risks extinction, practitioners are allowed to abstain from collecting - but it is recommended that they be prepared to explain their decision. At the end of the section, this position is situated along with others in a conceptual framework that identifies a range of possible positions in the debate. Finally, the paper argues that a slight adjustment in official procedure is warranted. Although current recommendations about proper collecting procedure come very close to accommodating both sides of the dispute-what have been here termed the collections, curation, and research side of things and the conservation biology sidethe rules do slightly favor collection over conservation. But there are reasons, explored in the conclusion of the paper, which should appeal to both sides - reasons that urge in favor of adopting a more neutral position. So, the paper ends by recommending a slight adjustment to taxonomic policy: practitioners are advised to be prepared to articulate their reasons either for collecting or not collecting, in cases where collection is thought to risk extinction.

\section{Free Bird}

In August of 1988, a young biologist from the UK was driving towards a hospital on the outskirts of Bulo Burti along the Shabeelle River in central Somalia, when a black and white bird the biologist could not identify flew past (Yoon 1992; Collar 1998). The biologist's name was Edmund F. G. Smith, and he was in Somalia contributing to scientific research funded by the British government, research dedicated to eradication of the tsetse fly (Collar 1998). When Smith later returned to the area, in October, he again saw the bird and continued to see it on most weeks when he visited the hospital grounds. The bird was obviously a shrike, and it fed in a manner common to members of its apparent genus, Laniarius: traveling the same feeding route each day, hopping along the ground or on very low branches deep inside an Acacia bush, and flying from one bush to another after an hour or two spent within each (Smith et al. 1991). But the shrike's coloring was unusual, and it did not fit any of the patterns or size of the organisms of known species within the genus. After consultation with Smith, a local bird conservationist named Osman Gedow Amir trapped the bird on January 5, 1989 (Smith et al. 1991; Collar 1998).

Even with the bird held in captivity it could not be conclusively identified as belonging to any of the known species of shrike recognized by ornithologists and expected in or around that area. On January 19, 1989, a telex from Smith was received at the Cambridge, UK offices of the International Committee for Bird Preservation (ICBP). This organization, founded in 1922 and now more commonly known as BirdLife, describes itself as "the World's Oldest International Conservation Organisation" (http://www.birdlife.org/worldwide/partnership/our-history). Smith's telex inquired:

\footnotetext{
${ }^{5}$ Biology includes both neontology, the study of extant species, and paleontology, the study of extinct ones.
} 
Have found new species of bird in Somalia... Specimen in captivity for two weeks. Believed very rare and local... Is record acceptable without dead specimen? (Collar 1999, 364)

And Nigel Collar, then Acting Director of the ICBP, replied that same day:

We urge you to keep bird alive. Photograph it from every angle, video it, tape its voice, measure everything and, if possible, seek a blood sample: but do not kill it. (ibid)

Back in Somalia, these recommendations were followed to the letter. The bird could not be sexed, but a blood sample was taken and contact was made with two Danish scientists in Copenhagen, about the possibility of using a blood sample to genetically identify the bird. Thanks to an airline baggage error, a case of lost luggage kept the deep-frozen parcel of fresh blood from ever reaching its destination. Eventually the scientists in Copenhagen had to make do with some smears of dried blood on paper and molted feathers instead - residues that the ICBP managed to obtain and pass on (Smith et al. 1991).

By this time Smith, the young British biologist, had left Somalia (in March of 1989) and care of the captive bird had been transferred to another foreign scientist, a German named JanUwe Heckel. Heckel, like Smith, was a researcher contributing to foreign governmental aid to Somalia, doing work focused on the eradication of local pests (Collar 1998). But Heckel's focus was on the red-billed weaver (Quelea Quelea quelea) - possibly the most numerous nondomesticated bird in existence, and a very effective consumer of grain from cereal crops intended for human consumption. When civil unrest spurred the unexpected and hasty evacuation of Heckel from the capital city of Mogadishu, the German scientist was forced to choose between abandoning the bird or taking it with him back to Germany. Heckel managed to export the shrike and to successfully care for it, until the situation in Somalia settled enough for him to return with the bird and release it (Smith et al. 1991).

By all known accounts Heckel's care of the bird during its sojourn in Germany was absolutely stellar. While in captivity, the bird's activity was generally quite robust and healthy. It ate crickets, cockroaches, geckos, and lizards. The bird was relatively quiet for a shrike - it did not call and duet as normal, though this may have been due to the absence of a partner. It did churr at dusk and dawn, when flying to and from its roost; it also uttered a low chalk call when feeding. And it frequently made a sound, "an ascending disyllabic poo-eeh whistle" (Smith et al. 1991, 233), that it was never heard to make while it was in the wild.

In an ironic twist to the narrative, the very eradication efforts targeting the tsetse flythose which had drawn the young biologist Smith to the shrike's locale in the first place (Collar 1998) - also turned out to have destroyed any remaining local habitat suitable for the captured bird to be released in. At the time of the bird's discovery, there had been a decent stretch of riverine Acacia habitat located not far from the hospital grounds on which the bird had been found, the sort of territory similar enough to that in which the bird was originally found: a swath of thicket about a kilometer wide and containing some woodland along the river, beginning about $15 \mathrm{~km}$ north of Bulo Burti and continuing for around another $50 \mathrm{~km}$. But the successful near-eradication of the tsetse fly in this zone had opened the area up to much more extensive use by humans than ever before. By the time Heckel was able to return to Somalia (in March of 1990), that stretch of oncedense and altogether impenetrable vegetative habitat was now shot through with trailblazing, livestock grazing, and cooperative farming efforts. There was also quite a bit of ongoing warfare in the Bulo Burti area, with many refugees fleeing from and through the zone (Smith et al. 1991).

Together, Heckel and Amir (the local ornithologist who had originally trapped the bird) decided that there was no territory anywhere nearby in which it would be suitable to release the shrike. They selected an ecologically related site, also located along the Shabeelle River but some distance south of Bulo Burti, in the Balcad Nature Preserve - an area that had been "protected efficiently since 1985" (Smith et al. 1991, 234). After a week spent in an open-air enclosure while 
acclimatizing to the region and feeding on insects within the Acacia scrub, the bird was deemed fit to survive in the wild. On March 23, 1990, following more than 14 months in captivity and approximately $175 \mathrm{~km}$ away from where it was initially captured, the shrike was released (Smith et al. 1991).

Less than a year later, in the January 1991 issue of Ibis — one of the top ornithology journals in the world - the discovery of a new species of shrike from Somalia, named Laniarius liberatus, was announced (Smith et al. 1991, TSN 560703). Criticism and debate has continued pretty much unabated ever since. The species has been issued a taxonomic serial number (TSN) by the Integrated Taxonomic Information System (ITIS), and for some time, many ornithological authorities (such as The Clements Checklist of the Birds of the World, The Howard and Moore Complete Checklist of the Birds of the World, and the IOC World Bird List) acknowledged and listed the species. But in 2008, a molecular sequence-based phylogeny of the genus Laniarius was published in Molecular Phylogenetics and Evolution (Nguembock et al. 2008). The paper had four authors - one of whom, Jon Fjeldså, was also an author on the original Laniarius liberatus paper. Despite claims made in the 1991 paper such as "There is thus no reason to believe that the bird is a hybrid between any of the examined species or a colour morph of one" (Smith et al. 1991, 232), the 2008 paper purportedly shows that Laniarius liberatus is, after all, a color morph of another, already known species: Laniarius erlangeri, described by the German naturalist Anton Reichenow in his Die Vögel Afrikas (Reichenow 1905, TSN 916269). Additional molecular and morphological data - the most recent available, published in the Bulletin of the British Ornithologists' Club (Finch et al. 2016) - indicates that Laniarius erlangeri is itself a junior synonym for another shrike discovered by Reichenow even earlier, Laniarius nigerrimus (Reichenow 1879, TSN 916883). Some consider Laniarius nigerrimus to be merely a subspecies within a larger species group; the relationships between it and Laniarius ferrugineus (Gmelin 1788, TSN 560699), Laniarius aethiopicus (Gmelin 1789, TSN 560691), Laniarius major (Hartlaub 1848, TSN 916268), and Laniarius sublacteus (Cassin 1851, TSN 916270) are all still contested. ITIS currently recognizes all five of those groups as their own species, however, whereas Laniarius erlangeri and Laniarius liberatus are now considered invalid. ${ }^{6}$

\section{Characterizations}

So what is going on here-should Smith et al. (1991) have collected the shrike? Should field biologists harvest specimens from what might be extremely vulnerable populations? This issue is difficult to characterize well, for assorted reasons. One such reason is, as the case study indicates, the sheer number and diversity of the concerns raised by the issue. Here are just some of the things that the parties engaged in the general debate are worried about: they are worried about cementing, deciphering, and upholding taxonomic standards; they are worried about accommodating many different kinds of biological, ecological, and historical situations with their taxonomic standards; they are worried about establishing priority, validation, reproducibility, and fraud; they are worried about contributing to extinction; they are worried about being perceived by the public as contributing to extinction; they are worried about preserving whatever scientific and ecological information they can in the face of what seems like an inevitable holocaust of extinction; they are worried about how to model good ecological behavior and how to avoid hypocrisy in their behavior and the modeling of that behavior; they are worried about colonialist and imperialist interpretations of their collecting behavior in certain regions; they are worried about amateurs blundering around in the field; they are worried about the evolution of permitting restrictions and

${ }^{6}$ Invalid is the ITIS term for a failed attempt at naming a new species. The ICZN uses the term unavailable instead. This is because a name that is introduced to describe a purportedly new species, but which is later rejected, is no longer available to be used as a name for any further taxonomic delimitation attempts. 
compliance with those restrictions; they are worried about the impacts of this debate on sources of funding and other resources; they are worried about the future of museums; they are worried about what future technological developments might mean for the value and application of museum collections; they are worried about how to preserve and maximize the kind of information that they can extract from their collections; they are worried about how to relate certain kinds of information in their collections to other kinds of information (such as genotypic to phenotypic information); they are worried about the loss of information that they do not currently have access to but one day might have; they are worried about how the ongoing, tendentious discussion of collecting voucher specimens from vulnerable populations might impact their ability to collect extensive specimen series from less vulnerable populations for other research purposes; they are worried about undue influence on and control of specialist taxonomic pursuits by prestigious generalist journals; they are worried about a divide or even just the appearance of a divide between the cultures of collection and conservation; they are worried about tension between individuallevel, population-level, and ecological-level approaches to conservation; they are worried about the way successful implementation of conservation-based public policy is often dependent upon the taxonomic practices of species discovery and description; they are worried about the complicated and fraught relationship between science and policy; they are worried about how to make and evaluate environmental and ethical appeals in science; and they are worried about which amongst all these concerns are properly scientific and which are mere sentiment. ${ }^{7}$ It is difficult to be cognizant of all these concerns at once, and to take them all into account when characterizing the issue, not to mention attempting to arrive at a resolution.

Another source of difficulty in successfully framing the issue comes from the fact that this debate has been going on for quite some time now, and in that time disagreement appears to have gotten more rather than less extensive, and over that time tempers seem to have flared a bit rather than cooled. There have been mischaracterizations and misunderstandings, corrections and objections, accusations and replies, and even a few emotional outbursts. It is not all that surprising, as this is a case where the stakes are high, disagreement is extensive, and resolution uncertain. But this highly-charged behavior can be unhelpful. In an attempt to characterize this facet of the debate without escalating it, I will now discuss - in general terms only—just one illustrative example of this sort of pitfall from each side of the dispute, both of which commonly trap correspondents.

On the one hand, proponents of restricting collecting, especially in the case of potentially vulnerable populations, have been liable to sketch their opponents as isolated, oblivious stamp collectors. On this portrayal, the problem is with dusty systematists who just want as much information as possible, regardless of the consequences. Underlying this portrayal is the assumption that the information being sought by the opponent is trivial information. But I do not think this is an accurate characterization even of those who want to collect what might be the last few individuals of a threatened population. I think that the people advocating such a drastic practice think it is worth it because it is the only way to salvage anything of value from what is already an extremely dire situation. And they think the information that could be obtained will likely be highly valuable. Of course, it is possible to disagree with this assessment - but simply characterizing that practice as valueless fails to engage with the opponent. I doubt that many scientists would ardently defend a practice that they themselves believe has little or no value. Appreciating the actual position and possibly changing minds here, or reaching an agreement, requires engaging with the actual reasons for and against thinking that said practice does or does not have sufficient value to justify it - not just asserting that the value it has is trivial.

\footnotetext{
${ }^{7}$ For a representative sample of authors each articulating a subset of these concerns, see LeCroy \& Vuilleumier (1992); Collar (2000); Bates et al. (2004); Dubois \& Nemésio (2007); Donegan (2008); Nemésio (2009); Krell \& Wheeler (2014); Minteer et al. (2014); Peterson (2014); Marshall \& Evenhuis (2015); Ceríaco, Gutiérrez, \& Dubois (2016); Aguiar, Santos, \& Urso-Guimarães (2017); Dubois (2017); and Krell \& Marshall (2017). For a somewhat terrifying demonstration of what can be at stake here for an individual practicing scientist, see Johnson (2018).
} 
On the other hand, proponents of allowing collecting even in the case of potentially vulnerable populations have been liable to characterize their opponents as sloppy, ill-formed, and unscientific activists rather than intellectuals. On this portrayal, the problem is with anthropocentric or even squeamish environmentalists who are somehow participating in scientific practice but without the proper discipline or mindset. Underlying this portrayal is a belief that some considerations (such as those pertaining to accuracy, precision, and objectivity) trump others (like those having to do with appearance, perception, and impact) in science. Again, I think that this is an inapt characterization of even those who want to forbid the collecting of any specimens from, for instance, critically endangered populations. I think that the people advocating such limitations on collecting practices think it is worth it because they would rather take any chance at preserving the system under study than potentially perturbing it to the point of destruction. They think that the chance to save the system is worth more than securing a fragment of the system for study after it is gone. And of course, it is possible to disagree with this assessment—but simply characterizing the approach as unscientific is just another way of failing to engage one's opponent. I doubt that any scientists are happy with the rampant destruction of the systems they are trying to study, especially those systems that can never be recovered. Appreciating this position and possibly changing minds or even coming to an agreement requires engaging with the strategic assessment being made here and with the tactical judgments being made in support of that assessment—not just dismissing the assessment and related judgments as unscientific.

In sum, there are many considerations in play here and various traps of characterization which are quite easy to fall into-and this is all just what a review of the relevant scientific literature reveals. Philosophers who wish to approach and understand this issue are likely to bring other considerations to the table, as well as be subject to the pull of alternative attractor states that are also worth avoiding.

Environmental ethicists, for example, might be liable to analyze the situation according to those ethical frameworks that have tended to dominate their discipline - to explore how notions such as the land ethic, animal liberation, inherent worth, and the right to life might relate to the case. But it is worth keeping in mind that those concepts and approaches have generally been designed with other problems and purposes in mind, and by persons external to the relevant disciplines of field and conservation biology. It would be really excellent if we could devise a response to the current situation that recognizes - insofar as is possible - all and only the relevant considerations in play. It would be even more excellent if we could devise a response that the relevant practitioners might recognize as valid and actionable. The salient question here is: when you are dealing with a biological or ecological system in crisis, should you prioritize trying to save the system, avoiding any risk to it that you can, or should you prioritize trying to save a bit of information about the system, even if obtaining that bit of information about the system might contribute to its destruction? The approaches of environmental ethicists are especially well designed to demonstrate and emphasize the experience and worth of organisms and the environment, but the question facing field biologists of both the conservationist and taxonomic stripes is one that generally presumes such worth, while not quite knowing how best to defend or salvage which pieces of it in the face of its overwhelming demolition. So, environmental ethicists weighing in on this issue should keep in mind how they might need to deviate from their usual approaches in order to address this situation, one in which various forms of triage may be the only plausible options. They should also remember that their recommendations have to be appreciated and implemented in order to be effective. ${ }^{8}$

\footnotetext{
${ }^{8}$ Robert W. Loftin (1992) discusses the issue of scientific collecting in a piece published in Environmental Ethics. The paper attempts to combine considerations from the land ethic with those of animal liberation à la Mary Anne Warren (1983), and it almost concludes with a list of eight criteria that must be met in order for collecting to be justified: necessity, importance, novelty, least damage, mercy, maximum information, no long-term impacts, and no jeopardy to endangered species. But after this list is provided the paper actually concludes with a short vignette, about a somewhat small collection, "amassed by a rather mediocre ornithologist" (Loftin 1992, 264), which was bequeathed to an eminent ornithologist who discovered, amongst all the rather commonplace material, a single specimen that provided the first and so far only evidence of that specific bird being present in that particular state. The author of the paper (Loftin), who
} 
Alternatively, philosophers of biology might be tempted to turn to aspects of the species problem, along with questions of naming and reference, in order try and settle this dispute. The role that type specimen collection plays in taxonomic practice has certainly been noted in the philosophy of biology literature (e.g., Hull 1978; Haber 2012). We could ask: are type specimens required for establishing, naming, and referring to species? And do extant species require a voucher specimen to serve as the type material? These are relevant questions (which will be explored in what follows), but they are not questions that can by themselves resolve the issue of whether voucher specimen collection is justified when collection risks extinction - and it is important that we do not mistake them for such. Imagine the possible outcomes of a philosophical investigation focused on what is required for establishing, naming, and referring to extant species: we could determine that type specimens are required for establishing, naming and referring to species, and that extant species require a voucher specimen to serve as the type material; we could determine that type specimens are required for establishing, naming, and referring to species, but that extant species do not require a voucher specimen to serve as the type material; we could determine that type specimens are not required for establishing, naming, and referring to species, but that extant species require a voucher specimen to serve as the type material when such material is used; we could determine that type specimens are not required for establishing, naming, and referring to species, and that extant species do not require a voucher specimen to serve as the type material when such material is used. And yet, whether or not establishing, naming, and referring to extant species requires a type specimen, whether or not that specimen must come in the form of a harvested and prepared organism—none of this settles the question of whether a voucher specimen should be collected when collection risks extinction. For instance, even if such collection is required to name a new species, we can still ask: is naming the new species worth the risk? And even if a new species can be named without collecting a voucher specimen, we can still ask: are there other reasons for collection which justify risking the extinction of the species? There is simply no avoiding these normative questions when it comes to exploring and resolving this issue. The role that specimens play in establishing, naming, and referring to species is relevant but not decisive; the value of establishing, naming, and referring to species also has to be ascertained, and compared with other values, many of which have to themselves be assessed.

Speaking of values and norms: it would be similarly easy for a philosopher of science to learn just enough about this debate to decide to view it as a dispute between those prioritizing epistemic values (on the collections side) versus non-epistemic values (on the conservationist side). But all sides rely on frequent appeals to, for instance, shared conservationist values; all sides advocate for clarity of and compliance with a rigorous taxonomic code, for shared epistemic reasons. ${ }^{9}$ The underlying disagreement here stems from the combination of high stakes and deep uncertainty-from being unsure about how best to observe and preserve certain biological and ecological objects of scientific study that are irreplaceable and yet deeply threatened - plus differing assessments of how best to respond to this deadly combination of risk and uncertainty. Thankfully, there is at least one way to reveal and resolve such underlying

is both an ornithologist and a philosopher, then declares that he thinks the acquisition of that knowledge was worth the life of that bird.

But the list just provided does not appear to have been consulted at all in the generation of this judgment, and it seems highly likely that many of the birds in that collection were collected in a way that violates the requirements of the list - what about all the "commonplace" birds that had to be collected in order for the amateur to happen upon something valuable? What about the fact that it does not seem like this collection was available for study prior to the death of the collector? What about the "least damage" and "mercy" requirements, since we do not seem to know anything about how the birds were collected? I could go on, but the point is that not even the creator of this list of criteria for justified scientific collecting seems to be using the list when generating his assessment of whether a particular episode of collecting is justified or not; the creator seems instead to be using the value of the information produced as a sort of trumping, retroactive justification. Field biologists need help figuring out whether and how to collect when they are actually in the field-before they know precisely how collecting or not collecting will turn out. 9 The exchange between Dubois \& Nemésio (2007), Donegan (2008, 2009), and Nemésio (2009) is especially demonstrative of this point. 
disagreement about how to respond to uncertainty while avoiding unhelpful traps: by seeking out contrast cases - especially, ones from areas where the stakes are lower.

\section{If We Hold On Together}

One place we might think to look for lower-stakes contrast cases could be outside ornithology but in other neontological realms. This would be a mistake. Although the initial incident that sparked this debate comes from within ornithology, the issue is by no means restricted to that domain. Since 1991, when Smith and colleagues explicitly appealed to risk of extinction - in order to justify their attempt to document the discovery of a new species of shrike without harvesting and depositing the typical voucher specimen, while advocating for the acceptance of other type material instead - similar reasoning has been deployed more and more frequently in other zoological domains. Novel taxonomic discovery and description has been proposed without a voucher specimen for reasons of extinction risk in, for instance, the following cases: that of a Tanzanian monkey (Jones et al. 2005), a lemur from Madagascar (Thalmann \& Geissmann 2005), a Brazilian capuchin (Mendes Pontes, Malta, \& Asfora 2006), a pink iguana from the Galápagos (Gentile \& Snell 2009), and a carpenter bee-mimicking fly from South Africa (Marshall \& Evenhuis 2015). ${ }^{10}$ So this issue arises not just for birds but also primates, reptiles, and insects.

Unsurprisingly, our closest relatives are especially well represented on the list of organisms for which extinction risk is apparently a particularly salient reason to be conservative about collecting. But it looks like this issue could arise for any kind of extant species - any species which currently exists and which is thereby subject to at least some degree of extinction risk. That is where the uniquely high stakes come from in these kinds of cases: the risk of extinction. So we should go outside the study of extant species in order to find some potentially illuminating, relatively low-stakes contrast cases. Paleontology, which mostly studies long-extinct species, could help us here. In what remains of this section, collecting norms from paleontology will be contrasted with collecting norms from neontology, in order to identify any shared collecting commitments which might be widespread and fundamental enough to form the basis for a consensus resolution to the ongoing dispute about what to do when collection risks extinction - a resolution that might appeal to disputants on both sides.

In 2013, the discovery of a novel allosauroid from the Cretaceous Period was reported in Nature Communications (Zanno \& Makovicky 2013). Siats meekerorum was an exciting find: the dinosaur was big, it likely ate other dinosaurs, it was probably an apex predator, and not much is known about such predators from its particular time and place. Much more is known, comparatively speaking, about the earlier, taxonomically diverse predator guilds of the Late Jurassic, as well as the later and taxonomically bereft phase of tyrannosaurid dominance during the latest Cretaceous. The discovery of Siats was initiated during a 2008 permitted dig in Utah conducted by investigators from the Field Museum of Natural History in Chicago, and credited to a postdoc on the dig. It took several years to successfully excavate the discovery site, and further years of work to prepare and analyze the fossils in-house at the Field Museum. The dinosaur was named Siats for a monster of indigenous (Ute) myth and meekerorum for the Meeker family who had funded the very postdoctoral endowment that had supported the position of the young paleontologist who made the discovery. It was a stellar find, and the publication announcing its discovery documented not just the find of a new species but also what the discovery of this specimen and its taxon

\footnotetext{
${ }^{10}$ This is a conservative list intended to identify especially those cases which involve no voucher specimen collection explicitly due to risk of extinction. There are other kinds of cases where vouchers cannot accompany new species discovery and description for other reasons, like that of the size of the specimen involved, its inaccessibility (e.g., deep in the ocean), difficulty preserving its body, or the simple fact that it escaped. See Krell \& Marshall (2017) for a more inclusive and extensive list of novel taxonomic discovery and description attempts sans voucher but for various, including unspecified, reasons.
} 
likely indicated in terms of composition of the relevant predator guild, niche inhabitance and replacement, biogeographic history of extirpation and dispersal, phylogenetic diversity, and endemism.

What is especially interesting about this discovery for our purposes, however, is that all this taxonomic and reconstructive work was based on a species known only from fragments of two partial individuals. The holotype of Siats meekerorum - the name-bearing specimen of the species - consists primarily in the form of several partial vertebrae (5 dorsal and approximately 13 caudal), one partial ilium, and one partial fibula. There are a few teeth but no other recognizably cranial materials, and there are many other fragmentary elements associated with the find but of undetermined origin. Because most of the recovered vertebral neural arches are unfused, the fossilized remains are thought to be those of an immature individual (a juvenile). There are also a few even sparser fragments thought to be derived from a second individual — just a neural arch and chevron from somewhere along the tail, a toe bone, and "several indeterminate bone fragments" (Zanno \& Makovicky 2013, 2).

Comparing this bit of paleontological taxonomic practice with that of the ornithologists might lead one to think the comparison reveals wildly dissonant taxonomic standards between the two fields. And in a sense, it does: Zanno and Makovicky (2013) report the discovery of a new dinosaur species on the basis of a jumble of partial bone fragments from one individual that would be approximately 4,000 $\mathrm{kg}$ when fully grown, plus a scant handful of fragments from possibly another individual... and no one bats an eye. Smith et al. (1991) report the discovery of a new bird species after weeks-long observation of an individual in its natural habitat, capturing and caring for and examining the bird over a period of months, taking blood samples and extracting its DNA, collecting moulted feathers, taking at least 50 color photographs, audio recording its calls, and videotaping it. But because the bird was released rather than killed so that its skin and skeleton could be preserved for further study... the ornithological community erupts in a decades-long furor. The paleontologists have much less in the way of evidence, but they do not object to novel claims of taxonomic discovery made on that basis; the ornithologists have much more in the way of evidence, and they do object. There is apparent dissonance here, between the fields, in terms of both the amount of evidence typically acquired and the standard of evidence typically required. This dissonance is initially puzzling: no doubt, there was a lot of information contained in that skin and that skeleton which no ornithologists can now access or examine; but notice how much paleontologists can get out of just a few partial pieces of fossilized skeletons! Why are paleontologists so happy to call a scattered, degraded, and partial assortment of fossil fragments enough for a type specimen, while ornithologists reject a much more extensive collection of biological and other material as inadequate type material? Is not the collection of DNA and blood and feathers and audio and video and photographs and GPS and behavior and ecology of the shrike enough?

One might to be tempted to retort, at this point, that obviously the DNA and the feathers and the other documentation was not actually enough - the purported discovery of the supposedly new species of shrike was eventually overturned, after all. But that is not really the problem here. Clearly, enough material was collected in order for the original taxonomic assessment to be re-evaluated, refined, and eventually rejected. And overturning is something that can happen even when ornithologists follow all the typical rules for naming a new species. Consider the recent overturning by Finch et al. (2016) of Reichenow's early-twentieth century species designation for Laniarius erlangeri. Relationships between the pied and all-black forms of various east African shrikes have long been contested. Reichenow thought that, amongst the all-black specimens, those initially discovered in Kenya (L. nigerrimus) should be distinguished at the species level from those later discovered in Somalia (L. erlangeri). But the latest molecular and morphological analysis (Finch et al. 2016) seems to indicate that although pied and all-black forms generally belong in separate clades ${ }^{11}$ the all-black forms of L. nigerrimus and L. erlangeri are not,

${ }^{11}$ The one pesky exception to this general rule is, of course, the not-quite-collected specimen purportedly belonging Laniarius liberatus. That shrike was pied, but the molecular analysis of Nguembock et al. (2008) and Finch et al. (2016) both group it along with, respectively, what was formerly L. erlangeri and what is now L. nigerrimus. 
despite their endemism, distinct species after all. Since L. nigerrimus was discovered (in 1878) before $L$. erlangeri was (in 1905), that makes $L$. erlangeri a junior synonym of $L$. nigerrimus. This sort of upheaval is pretty routine.

Or consider the case of another, more recently discovered African shrike: Willard's Sooty Boubou from the Albertine Rift. In 1997, three ornithologists did some collecting while surveying a privatelyowned banana plantation in southern Uganda, within a part of the Albertine Rift system. They collected four black Laniarius specimens that looked on the basis of size and plumage to belong to $L$. poensis holomelas - but the ornithologists in question also noted the unusual, blue-gray eyes of the specimens. Expected eye color would be reddish-black. There was also another specimen, one collected in Burundi in 1991 and held at the Field Museum in Chicago, with unusually light eyes. No mention of this eye color could be found in the published record and eventually, Gary Voelker and colleagues were able to put together enough morphological, molecular, biogeographical, and phylogenetic data to argue that these five specimens represented a new species. In 2010, they announced the discovery of Laniarius willardi in the pages of The Auk, another of ornithology's top journals (Voelker et al. 2010). The species was named $L$. willardi for David Willard, a longtime contributor to ornithology at the Field Museum, and its common name (Willard's Sooty Boubou) refers to Willard as well as to the bird's dark plumage. Nonetheless it is possible that one day another group of ornithologists will come along and argue that, despite their blue-gray as opposed to red eyes, specimens of the supposed species Laniarius willardi are actually just variants of Laniarius poensis holomelas after all. That sort of thing can happen even when you follow all the rules.

No one will write vehement letters to Science and Nature if Laniarius willardi gets overturned; there will not be hundreds of museum specialists lining up to sign their name to feisty missives declaring that the Code of the ICZN must be hastily amended in order to prevent such a mistake from ever happening again. Perhaps the natural thing to wonder now is just: are neontologists somehow testier than their paleontological counterparts? Maybe paleontologists simply do not police the boundaries of their epistemic standards for taxonomic discovery and description the way ornithologists and other zoologists do. Yet again, it would be a mistake to think this way.

In 2000, the discovery of a "remarkable" new maniraptoran theropod was announced in a University of Kansas publication dedicated to "Paleontological Contributions" (Burnham et al. 2000). In 1993, a specimen was discovered by Wes Linster in the Two Medicine Formation near Bynam, Montana that eventually necessitated the delimitation of a new genus and species - that of Bambiraptor feinbergi. Again, this was an extremely exciting find: the specimen was more than $90 \%$ complete, it was discovered in excellent condition, its posture could be estimated with confidence, and it had obvious birdlike features. So, one might wonder why the discovery of such a charismatic and important specimen - twice the size of most Archaeopteryx specimens and nicknamed "Bambi"-would be reported in such an obscure venue. Why not Nature Communications this time, or at least the Journal of Vertebrate Paleontology? I will let the paleontologist Kevin Padian explain:

The specimen of Bambiraptor feinbergi, a birdlike dinosaur collected in Montana, does not yet have a permanent home in a public museum... because the specimen is still privately owned, its publication is problematic for many paleontologists. The Society of Vertebrate Paleontology, for example, has an ethics statement opposed to the commercial sale of important vertebrate fossils and will not publish in its journal any specimens not in the public trust. ... The specimen in question was excavated and sold by then-amateur collectors. Some parts of the skull and other bones of the skeleton were severely damaged. Consequently, it is difficult to tell by comparisons whether this is a juvenile specimen of a new taxon or of a taxon that is already known. ...Because the specimen is mounted in a restored position, it is difficult to study the original material, or to tell what is original, what is restored, and what it has to tell us... (Padian 2000, 1173)

This example shows that paleontologists are sensitive to their discipline's standards for taxonomic discovery and description, too. There are compelling epistemic and ethical reasons for having and upholding strict standards for access to data and data reproducibility. For these reasons, paleontologists vigorously police their own standards. 
By now I have used a set of contrast cases to suggest and then reject several candidate relations between collecting norms in neontology and paleontology - those which most readily suggest themselves. In order of presentation, the considered relations were: perhaps the collecting norms in these two fields are just wildly dissonant; perhaps overturning is an indicator of poor collecting practice; perhaps neontologists are more sensitive to their collecting norms than paleontologists are. Again in order of presentation, the contrast cases were: paradigmatic taxonomic delimitation attempts in paleontology (Siats meekerorum), atypical taxonomic delimitation attempts in ornithology (Laniarius liberatus), paradigmatic taxonomic delimitation attempts in ornithology (Laniarius erlangeri and Laniarius willardi), and atypical taxonomic delimitation attempts in paleontology (Bambiraptor feinbergi). Altogether, these cases demonstrate that if you are attempting to scientifically document the discovery of a new species, extinct or extant, then you are expected to at least try and collect just about as much material as you can without introducing worthless redundancy, without wasting resources, and without violating permitting or other restrictions. In other words, there is actually a consonant collecting norm shared between the neontological and paleontological communities, absent considerations of extinction risk. And it looks to be something like "collect as much as you can without redundancy, waste, and violations."

The interesting thing about the "collect as much as you can" rule is that it generally gets translated into more material in the case of extant species than it does with long-extinct ones. This is what generates the first impression - from looking just at the amount of evidence typically acquired and required - that the two fields have two wildly dissonant standards when it comes to specimen collection and taxonomic discovery. The case of Siats meekerorum shows that paleontologists are willing to name new species when they have only a fraction of a fossil specimen; whereas the ornithologists are upset that for Laniarius liberatus they got blood, feathers, photos, video, sound recording, geographical location, and ecological information - but no dead body. This looks a lot like two fields with drastically divergent standards for the collection of material when discovering and describing new species. And yet, on another way of looking at it — one based on the portion of available evidence that is supposed to be collected - these two fields actually share the very same standard. That standard is: follow regulations while maximizing the collection of material and minimizing redundancy and waste. ${ }^{12}$

Let us call the viewpoint that emphasizes the different amounts of evidence gathered an outcomebased view, and the perspective that notices the "collect as much as you can rule" a procedural view. Attending to the latter perspective leads to the meta-realization that procedure matters a lot in both communities. $^{13}$ The assorted case studies demonstrate that, for both communities, if you follow the collecting rules and yet still turn out to be wrong about discovering a new species, no one will make a fuss. But if you fail to follow these rules, your conduct is likely to be critiqued regardless of whether you turn

\footnotetext{
${ }^{12}$ Imagine two foraging communities that each spend the day scrounging for berries and firewood. One community lives in an abundant forest; the other in a rather more punishing steppe. Both sets of foragers obey the rule "collect as much as you can each day." Because of what is available to be found in their different environments, the forest foragers tend to think of a good collecting day as one which pulls in X amount of berries and Y bundles of firewood, whereas the steppe foragers think of a good collecting day as one which pulls in one-fifth of X amount of berries and one-tenth of Y bundles of firewood. Just looking at these two very different outcome-based notions of what counts as a "good" collecting day, you might think that these two communities have different standards for what counts as good collecting - and in one sense, they do. But in another sense, these two communities have exactly the same standard for what counts as good collection. The procedural standard both are following is that of collecting as much as you can. ${ }^{13}$ A reviewer suggests that actually, what matters most to both the neontological and paleontological communities is having the bodies of organisms - a perspective which might be termed a sort of habeas corpus view. But this position cannot genuinely be the one adopted by paleontologists, because fossils are not bodies. Taphonization (the process of fossilization) generally leads to the replacement of most if not all of the organic materials that bodies are made of (for an introduction to taphonomy, please see Behrensmeyer, Kidwell, and Gastaldo 2000). Fossils, to put it bluntly, are rocks. They are records of bodies, not bodies themselves - just as a video of a shrike is a record of a body, but not a body itself. Sometimes original, organic biomolecules are (partially) preserved in fossils - just as a blood sample or a moulted feather (partially) preserves original, organic biomolecules from an organism. Neither the type specimen for Siats meekerorum nor that proposed for Laniarius liberatus are bodies.
} 
out to be right or wrong about discovering a new species. In other words, procedure matters - regardless of risk of extinction, or taxonomic outcome.

One thing we can infer from this meta-realization about procedure is that, for extinction risk to be recognized as a legitimate constraint on collecting in ornithology and other zoological areas, that constraint would probably have to be built into official procedure - just as the other, currently-recognized constraints are. Right now, the norm is something like "collect as much as you can without redundancy, waste, and violations." Three constraints on collecting have already been recognized and legitimated — constraints that stipulate the avoidance of redundancy, waste, and rule-breaking. Do the ornithologists and other studiers of extant species need to recognize a fourth constraint, one on collecting when it risks extinction? What does current policy have to say on this matter?

\section{Resolutions}

Since it is procedure that matters, perhaps it is finally time to turn to what the official rules have to say. This raises a pair of questions: what exactly do the rules say, and what ought they to say? Interestingly, the ICZN's official rules (also known as "the Code") for naming zoological species have never absolutely or uncontroversially ruled out even current claims of novel taxonomic discovery without the deposition of a voucher specimen. There are various reasons for this. For one, the deposition of voucher specimens as holotypes is a relatively recent practice. For much of our taxonomic history, illustrations based on collected specimens served as zoological holotypes (this is still common practice in botany). In this prior era, the original specimens were often destroyed after the creation of the illustration and its deposition as the holotype. For another, various zoological sub-domains sometimes have non-standard traditions with respect to the deposition of voucher specimens. Holotypic specimens for whale species, for instance, can be hard to collect and store due to their size as well as the depth at which they are found. Certain entirely soft-bodied organisms can be difficult to preserve and so those zoological practices can tend to have their own vouchering traditions. And sometimes stuff just escapes or gets lost or something unpredictable or unexplainable happens. So, there are historical, biological, and practical reasons to be accommodating of various cases and procedures.

The current edition of the ICZN's rules for the naming of animals is the Fourth Edition, and it dates to 1999. In a rather unfortunate but interesting turn of events, that particular edition of the rules enshrined an especially confusing articulation of the commission's view on whether voucher deposition is required for naming new species. The exact rule (16.4) bearing on the "fixation" of name-bearing types states that new species names - those introduced after 1999-must be accompanied, according to sub rule (16.4.1) by explicit fixation of a holotype or syntypes, and that according to sub-rule 16.4.2, "where the holotype or syntypes are extant specimens, by a statement of intent that they will be (or are) deposited in a collection" (International Commission on Zoological Nomenclature 1999). Crucially, fixation is a term which is often used in zoological practice to mean preparation of a specimen for preservation, but which could also here just mean conceptual fixation. And extant specimens can refer to either dead specimens of extant species or to living, as in still-extant, specimens. So one way to read the relevant set of rules and sub-rules is as requiring explicit fixation, in a broad sense, of some kind of holotype or syntypes when naming new species post-1999-along with the precisification that, if the holotype happens to be of the preserved specimen sort, then its professional deposition should be at least planned if not already executed. (Let us call this reading 1 of the Code). But another way to read the rules is as requiring fixation of a holotype or syntypes, in the you-must-prepare-a-fixated-specimen sense-along with the caveat that you are allowed, when dealing with a currently live specimen, to simply articulate your intent to eventually deposit the fixated specimen, say after its death. (Let us call this reading 2 of the Code). 
There are other dimensions to the confusion introduced by the way this issue was handled and discussed in the Fourth Edition of the ICZN's rules. ${ }^{14}$ But even just this one ambiguity (between readings 1 and 2 of the Code) suffices for our purposes: it establishes that the official ruling handed down in 1999 was significantly unclear. As a result of this unclarity, and as this unclarity became ever more publicly apparent and troublesome, various members of the commission spoke out in different attempts to set the record straight. Some confidently stated that ICZN rules have never required deposition of a voucher specimen prior to the naming of a new species (Wakeham-Dawson, Morris, \& Tubbs 2002; Polaszek et al. 2005). The current President of the ICZN recently declared that species could be named just from photographs (Pape 2016), while another member of the commission urged against that practice (Krell 2016). Certain commentators have announced that members of the commission cannot speak officially for the commission outside of the published text of the rules themselves (Dubois \& Nemésio 2007). Many have declared that whatever it is the rules are meant to say, they ought to be clearly, definitively, and officially re-articulated (e.g., Ceríaco, Gutiérrez, \& Dubois 2016).

Thankfully, the Code can be amended prior to the creation of an entirely new edition - as was done in 2012, in order to allow for species naming via publication in respectable online-only sources and according to certain procedures. ${ }^{15}$ And so, in March of 2017, Declaration 45 was issued by the ICZN, officially recommending that "when establishing a new species-group taxon without a preserved namebearing type" (International Commission on Zoological Nomenclature 2017, 96), such authors should: explain why they have not secured, preserved, and deposited a specimen; recount the steps they have taken or intend to take in order to collect a voucher; consult with relevant specialists; and provide extensive alternative material as documentation, as complete as possible, of the proposed taxonomic discovery and description. Note that this amendment to the Code is one which adds to its recommendations rather than alters its rules. This means that the commission suggests authors should follow these guidelines; but it also means that authors who fail to follow these recommendations will not necessarily or automatically have their species naming attempts invalidated. Finally, amending the Code in this way - to recommend but not require following these guidelines when naming a new species without a preserved name-bearing typeindicates that the intended meaning of the original language of the 1999 edition of the Code was that of reading 1 rather than that of reading 2 .

So much for what the Code actually says. What should it say? The commission obviously chose to resolve the issue in one particular way, but they could have adopted a different resolution from amongst many available options. Conservationist-minded correspondents on this issue have advocated for strict regulation of collecting practices when dealing with especially vulnerable populations. Collar (2000), for instance, argued that: collection from most critical species and certain endangered species should be prohibited; collection from all other critical and endangered species should be prohibited unless approved by an international committee, with approved collection of no more than 10 specimens occurring per year; and that collection of specimens from all other vulnerable species be capped at 25 per year for each such species, with such collections being promptly reported and monitored accordingly. Plus, said international committee should conduct a worldwide review of museum inventory of specimens from (in order of priority) extinct, critically endangered, endangered, vulnerable, and related species; and access to such material should be transformed from institutional to global. Also: the collection of specimens from taxa new to science should only proceed when collectors have reason to be confident that such collection will not endanger the species; the reasoning behind such confidence should be made explicit in the original taxonomic description when given; the collection of nationally threatened, locally threatened, and otherwise susceptible species should be done in a way that at least attempts to accord with the prohibitions

\footnotetext{
${ }^{14}$ See Dubois and Nemésio (2007) and Dubois (2017) for more thorough explication of all the relevant passages as well as the various contradictions and confusions introduced therein.

${ }^{15}$ Although this particular process of amendment to the code was not quite radical enough for all voting members of the commission (Minelli 2013).
} 
and caps introduced above; and collection in protected areas should generally be avoided. Finally, collecting museums should come together in forming a coalition, membership in which should be conditional on acceptance of all the above conditions (Collar 2000, 10-11).

On the other side of the issue, many taxonomically-minded correspondents have argued that there really is no genuine substitute - photographic or otherwise-for actual specimen collection. ${ }^{16}$ The general position here seems to be something like: more information is good; and if you can get it from a host of different sources, that is even better; but information from certain special sources is best; and actual physical specimens are one of these certain special best sources. Even correspondents such as those adopting a position like this one, however, seem to be willing to forego the collection of vouchers in certain circumstances - like when there is dire threat of extinction. For instance: Dubois and Nemésio (2007) proposed, and Dubois (2017) reiterated, the idea that the Code might be amended to clearly and explicitly require the deposition of vouchers when attempting to perform nomenclatural acts - except when the authors' reasons not to collect have been proposed to and approved by a special working committee of the ICZN developed precisely to evaluate these sorts of cases.

Considering this diverse set of candidate resolutions to the problem allows us to authoritatively assess and helpfully delineate the available conceptual space of solutions. For novel taxonomic discovery and description attempts, one could:

(a) forbid the collection of voucher specimens when collection risks extinction;

(b) forbid the collection of voucher specimens when collection risks extinction, except with explicit permission to do otherwise;

(c) discourage the collection of voucher specimens when collection risks extinction, recommending that those who do collect explain themselves;

(d) neither discourage nor encourage the collection of voucher specimens when such collection risks extinction, recommending that those who attempt novel taxonomic discovery and description in such circumstances explain their reasoning in either direction;

(e) encourage the collection of voucher specimens even when collection risks extinction, recommending that those who do abstain from collecting explain themselves;

(f) require the collection of voucher specimens even when collection risks extinction, except with explicit permission to do otherwise; or

(g) require the collection of voucher specimens even when collection risks extinction.

In this conceptual space containing positions (a) through (g), the middle position (d) is the neutral one between the two extremes at (a) and (g). The proposal of Collar (2000) resides somewhere around positions (a) and (b). The proposal of Dubois and Nemésio (2007) resides at position (f). The commission's recent Declaration 45 (International Commission on Zoological Nomenclature 2017) situates the Code's official ruling at position (e) - quite close to neutrality, but still privileging collection over conservation. That is unsurprising, given that the ICZN is primarily a taxonomic organization.

The recommendation of this paper, however, is for taxonomic practitioners and policymakers alike to endorse the neutral position (d). This is because the problem of whether to collect when collection risks extinction is - in the starkest of terms - the problem of whether to prioritize the preservation of systems for scientific study, or to prioritize the preservation of information for scientific study, when these two aims are in conflict with one another. ${ }^{17}$ Usually these two aims reinforce one another: preserving a system for scientific study (such as a species) creates opportunities to preserve information about that system; and preserving information about a system (such as a species) creates opportunities for preserving that system. But sometimes, in terribly unfortunate circumstances (like widespread ecological destruction), these two aims

\footnotetext{
${ }^{16}$ See Aguiar, Santos, and Urso-Guimarães (2017) for a representative account of why photography is no simple substitute for specimens. See Bates et al. (2004) for an illustrative account of why neither blood nor DNA are sufficient.

${ }^{17}$ Thanks to the editor of this special issue for pressing me to state this conflict explicitly, and in (close to) these terms.
} 
undermine one another. All parties to the dispute about specimen collection when collection risks extinction are committed to these joint preservationist aims - to preserving both systems and information for scientific study. And neither aim trumps the other. So, adopting a neutral position is best: one that favors none, and allows practitioners to choose either when they cannot have both.

\section{Conclusion}

This debate - about whether or not to collect voucher specimens from species thought to be at extreme risk of extinction - has been going on for quite some time now, and it is obviously a difficult debate to satisfactorily resolve. I have argued that the intractability of the debate does not result from obvious errors of, say, triviality or unprofessionalism on either side. Instead, the intractability of the debate results from the fact that there are reasonable scientific positions to be taken on both sides: there are good scientific reasons to say both that voucher specimens should and that voucher specimens should not be collected in these difficult and fraught cases. Impasses of this sort just are, unfortunately, things that can occur when stakes are very high and it is difficult or impossible to access the information you need, or to assess the value of the information you might obtain, prior to actually taking on the risk you are unavoidably confronting — risk which must be taken in order to better your informational position.

It would be lovely if field biologists could tell prior to harvesting whether the specimen they are considering collecting really is the only known member of a tiny, threatened population, or just an unusual morph of an abundant population. It would be nice if they could tell whether simply collecting a photograph and a blood sample would let them figure this issue out—but that may or may not be the case. Perhaps that will be all they need after all, and just that evidence will tell them so. Perhaps it will not be, but they will have released the organism, never to see the likes of it again. Perhaps it will be harvested after all, and detailed studies will reveal it was a member of a nascent population which may just have been decimated. Such high-stakes, deep uncertainty, risk-required-for-any-sort-of-reward situations are difficult positions to be in. Nonetheless, these are positions that neontological investigators sometimes find themselves in and it is possiblewith the help of paleontological comparison and taxonomic ruling - to make recommendations about how best to proceed when in them: with procedural care, and explanatory readiness.

If you collect a voucher from a critically endangered species and that action does not result in or contribute to the extinction of the species, but it goes extinct anyway, then you have saved something invaluable from a system that can never be recovered, and that is a fortunate thing to have done. If you refrain from collecting a voucher specimen from a critically endangered species, and that restraint along with whatever documentation of the species you manage to cobble together helps with its conservation, then you have helped to preserve and maintain the system for future study, and again that is a fortunate thing to have done. But if you collect a voucher specimen from a critically endangered species and that action results in or contributes to the extinction of the species, then you have helped to irreversibly destroy the very system you were attempting to study, and that is an unfortunate thing to have done. And if you refrain from collecting a voucher specimen from a critically endangered species and the species goes extinct anyway, then you have lost the chance to save something from the ashes of ecological ruin, and that is once more unfortunate.

Because it is not always possible to tell which of these outcomes will follow from any given choice to collect or refrain from collecting a voucher specimen, and because it is not always possible to tell whether a species really is critically endangered to the extent that collecting could contribute to or result in the extinction of the species, the best that we can do is to be aware of these risks and to be as careful as we can before either taking or refraining from action. Different 
practitioners are likely to favor absorbing certain kinds of risks over others, but all courses of action will require the absorption of some risk, and all courses of action will be capable of producing a bad rather than a good outcome at least some of the time. We can recommend that practitioners proceed in an informed and thoughtful manner, and that they be ready to articulate their reasoning in either direction, if and when things turn out badly. But adopting a neutral position like this one is the best we can do at this time.

\section{References}

Aguiar JJM, Santos JC, Urso-Guimarães MV (2017) On the use of photography in science and taxonomy; how images can provide a basis for their own authentication. Bionomina 12: 44-47.

Banks RC, Goodman SM, Lanyon SM, Schulenberg TS (1993) Type Specimens and Basic Principles of Avian Taxonomy. The Auk 110(2): 413-414.

Bates JM, Bowie RCK, Willard DE, Voelker G, Kahindo C (2004). A need for continued collecting of avian voucher specimens in Africa: why blood is not enough. Ostrich 75(4): 187-191.

Behrensmeyer AK, Kidwell SM, Gastaldo RA (2000). Taphonomy and Paleobiology. Paleobiology 26(4): 103-147.

Burnham DA, Derstler KL, Currie PJ, Bakker RT, Zhou Z, Ostrom JH (2000) Remarkable New Birdlike Dinosaur (Theropoda: Maniraptora) from the Upper Cretaceous of Montana. The University of Kansas Paleontological Contributions 13(1): 1-14.

Cassin J (1851) Description of new species of birds of the family Laniadae, specimens of which are in the collection of the Academy of Natural Sciences of Philadelphia. Proceedings of the Academy of the Natural Sciences of Philadelphia 5: 244-246.

Ceríaco LMP, Gutiérrez EE, Dubois A (2016) Photography-based taxonomy is inadequate, unnecessary, and potentially harmful for biological sciences. Zootaxa 4196: 435-445.

Collar NJ (1998) Undiscovered county: the non-collection of the Somali shrike. Bulletin of the African Bird Club 5(2): 136-137.

Collar NJ (1999) New species, high standards and the case of Laniarius liberatus. Ibis 141: 358-367.

Collar NJ (2000) Collecting and conservation: cause and effect. Bird Conservation International 10: 1-15.

Dalebout ML, Baker CS, Mead JG, Cockcroft VG, Yamada TK (2004) A comprehensive and validated molecular taxonomy of beaked whales, family Ziphiidae. Journal of Heredity 95: 459-473.

Dubois A, Nemésio A (2007) Does nomenclatural availability of nomina of new species or subspecies require the deposition of vouchers in collections? Zootaxa 1409: 1-22.

Dubois A (2017) The need for reference specimens in zoological taxonomy and nomenclature. Bionomina 12: 4-38.

Donegan TM (2008) New species and subspecies descriptions do not and should not always require a dead type specimen. Zootaxa 1761: 37-48.

Donegan TM (2009) Type specimens, samples of live individuals and the Galapagos Pink Land Iguana. Zootaxa 2201: 12-20.

Finch BW, Hunter ND, Winkelmann I, Manzano-Vargas K, Njoroge P, Fjeldså J, Gilbert MTP (2016) Redefining the taxonomy of the all-black and pied boubous (Laniarius spp.) in coastal Kenya and Somalia. Bulletin of the British Ornithologists' Club 136(2): 74-85.

Gentile G, Snell H (2009) Conolophus marthae sp.nov. (Squamata, Iguanidae), a new species of land iguana from the Galápagos archipelago. Zootaxa 2201: 1-10.

Gmelin JF (1788) Caroli a Linné systema naturae per regna tria naturae, secundum classes, ordines, genera, species, cum characteribus, differentiis, synonymis, locis $\left(13^{\text {th }}\right.$ Edition, Part I). Leipzig: Georg Emanuel Beer. 
Gmelin JF (1789) Caroli a Linné systema naturae per regna tria naturae, secundum classes, ordines, genera, species, cum characteribus, differentiis, synonymis, locis $\left(13^{\text {th }}\right.$ Edition, Part II). Leipzig: Georg Emanuel Beer.

Haber MH (2012) How to misidentify a type specimen. Biology \& Philosophy 27: 767-784.

Hartlaub G (1848) Description de cinq nouvelles espèces d'oiseaux de l'Afrique occidentale. Revue Zoologique par la Société Cuvierienne April 1848: 108-110.

Hull DL (1978) A matter of individuality. Philosophy of Science 45: 335-360.

Hustler K (1996) To collect or not to collect - that is the question. Bulletin of the African Bird Club 3(1): $53-54$.

International Commission on Zoological Nomenclature (1999) International Code of Zoological Nomenclature (Fourth Edition). London: The International Trust for Zoological Nomenclature.

International Commission on Zoological Nomenclature (2017) Declaration 45 - Addition of Recommendations to Article 73 and of the term "specimen, preserved" to the Glossary. Bulletin of Zoological Nomenclature 73(2-4): 96-97.

Johnson, KW (2018) The Ornithologist the Internet Called a Murderer. New York Times June 15, 2018.

Jones T, Ehardt CL, Butynski TM, Davenport TRB, Mpunga NE, Machaga SJ, De Luca DW (2005) The highland mangabey Lophocebus kipunji: a new species of African monkey. Science 308: 11611164.

Krell FT (2016) Preserve specimens for reproducibility. Nature 539: 168.

Krell FT, Marshall SA (2017) New Species Described From Photographs: Yes? No? Sometimes? A Fierce Debate and a New Declaration of the ICZN. Insect Systematics and Diversity 1(1): 3-19.

Krell FT, Wheeler QD (2014) Specimen collection: Plan for the future. Science 344: 815-816.

LeCroy M, Vuilleumier F (1992) Guidelines for the description of new species in ornithology. Bulletin of the British Ornithologists' Club Centenary Supplement 112A: 191-198.

Loftin RW (1992) Scientific Collecting. Environmental Ethics 14: 253-264.

Marshall SA, Evenhuis NL (2015) New species without dead bodies: a case for photo-based descriptions, illustrated by a striking new species of Marleyimyia Hesse (Diptera, Bombyliiadae) from South Africa. ZooKeys 525: 117-127.

Mendes Pontes AR, Malta A, Asfora PH (2006) A new species of capuchin monkey, genus Cebus Erxleben (Cebidae, Primates): found at the very brink of extinction in the Pernambuco Endemism Centre. Zootaxa 1200: 1-12.

Minelli A (2013) Zoological nomenclature in the digital era. Frontiers in Zoology 10(4): 1-7.

Minteer BA, Collins JP, Love KE, Puschendorf R (2014) Avoiding re(extinction). Science 344: 260-261.

Minteer BA, Collins JP, Puschendorf R (2014) Response. Science 344: 816.

Nemésio A (2009) Nomenclatural availability of nomina of new species should always require the deposition of preserved specimens in collections: a rebuttal to Donegan (2008). Zootaxa 2045: 114.

Nguembock B, Fjeldså J, Coulous A, Pasquet E (2008) Phylogeny of Laniarius: Molecular data reveal $L$. liberatus synonymous with L. erlangeri and "plumage coloration" as unreliable morphological characters for defining species and species groups. Molecular Phylogenetics and Evolution 48: 396-407.

Padian K (2000) A Home for Bambiraptor. Science 288(5469): 1173.

Pape, T (2016) Species can be named from photos. Nature 537: 307.

Polaszek A, Grubb P, Groves C, Ehardt CL, Butynski TM (2005) What Constitutes a Proper Description? Response. Science 309: 2164-2166.

Peterson AT, Lanyon SM (1992) New Bird Species, DNA Studies and Type Specimens. Trends in Ecology \& Evolution 7(5): 167-168.

Peterson AT (2014) Type specimens in modern ornithology are necessary and irreplaceable. The Auk 131: 282-286. 
Reichenow A (1879) Neue Vögel aus Ostafrika. Ornithologisches Centralblatt 4: 114.

Reichenow A (1905) Die Vögel Afrikas (Volume 3). Neudamm: Verlag von J Neumann.

Rocha LA, Aleixo A, Allen G et al (2014) Specimen collection: An essential tool. Science 344: 814-815.

Smith EFG, Arctander P, Fjeldså J, Amir OG (1991) A new species of shrike (Laniidae: Laniarius) from Somalia, verified by DNA sequences data from the only known individual. Ibis 133: 227-235.

Thalmann D, Geissman T (2005) New species of woolly lemur Avahi (Primates: Lemuriformes) in Bernaraha (central western Madagascar). American Journal of Primatology 67: 371-376.

Unsigned (2016) Virtual taxonomy. Nature 535: 323-324.

Voelker G, Outlaw RK, Reddy S, Tobler M, Bates JM, Hackett SJ, Kahindo C, Marks BD, Kerbis Peterhans JC, Gnoske TP (2010) A New Species of Boubou (Malaconotidae: Laniarius) from the Albertine Rift. The Auk 127(3): 678-689.

Wakeham-Dawson A, Morris S, Tubbs P (2002) Type specimens: dead or alive? Bulletin of Zoological Nomenclature 59(4): 282-284.

Warren MA (1983) The Rights of the Nonhuman World. In: Elliot R, Gare A (eds) Environmental Philosophy. University of Queensland Press, St. Lucia, pp. 109-134.

Yoon CK (1992) Rare Bird Illuminates Bitter Dilemma. New York Times April 28, 1992.

Zanno LE, Makovicky PJ (2013) Neovenatorid theropods are apex predators in the Late Cretaceous of North America. Nature Communications 4(2827): 1-9 (doi: 10.1038/ncomms3827). 